\section{Universos coloniais e 'enfermidades dos negros' pelos cirurgiões régios Dazille e Vieira de Carvalho}

\section{Colonial universes and the 'illnesses of blacks', by royal surgeons Dazille and Vieira de Carvalho}

André Nogueira

Doutorando do Programa de Pós-graduação em História das Ciências e da Saúde/Casa de Oswaldo Cruz/Fundação Oswaldo Cruz. Av. Brasil, 4036, 4 andar 21040-361 - Rio de Janeiro - RJ - Brasil guazo08@gmail.com

Recebido para publicação em fevereiro de 2011. Aprovado para publicação em março de 2012.
NOGUEIRA, André. Universos coloniais e 'enfermidades dos negros' pelos cirurgiões régios Dazille e Vieira de Carvalho. História, Ciências, Saúde Manguinhos, Rio de Janeiro, v.19, supl., dez. 2012, p.179-196.

\section{Resumo}

Analisa como as doenças que afetavam os cativos em áreas coloniais eram explicadas e nomeadas no tratado Observações sobre as enfermidades dos negros (1776), de Jean-Barthélemy Dazille, cirurgião francês das tropas na ilha de São Domingos. Sua tradução para a língua portuguesa pelo cirurgiãomor Antônio José Vieira de Carvalho (1801) indica a circulação de saberes entre os agentes que atuaram além-mar. Fortemente marcadas pelo neohipocratismo e por outras vertentes da medicina ilustrada, o tratado e a sua tradução suscitam considerações acerca dos perigos das 'zonas tórridas', das condições gerais de vida e trabalho 'dos negros' e de como tais questões eram remediadas.

Palavras-chave: escravidão e doenças; Jean-Barthélemy Dazille (1732/31812); medicina ilustrada; ilha de São Domingos; Minas Gerais.

\section{Abstract}

The article analyzes how the diseases that struck captives in colonial areas were named and explained in the treatise Observações sobre as enfermidades dos negros (1776), written by French surgeon for the troops on Santo Domingo Island, JeanBarthélemy Dazille. Its translation into Portuguese by Surgeon-Major Antônio José Vieira de Carvalho informs us about the circulation of knowledge among these agents who worked overseas. Strongly informed by neo-Hippocratism and by other lines of enlightened medicine, Dazille's treatise and its translation raises considerations about the dangers of the socalled torrid zones, the general living and working conditions of "Negroes," and the ways in which these were attenuated.

Keywords: slavery and disease; JeanBarthélemy Dazille (1732/3-1812); enlightened medicine; Santo Domingo Island; Minas Gerais. 


\section{Como pensar as doenças? Breves considerações teóricas}

Durante muitos anos, a visão das doenças como algo estável (ou linear) e de exclusivo pertencimento ao domínio da natureza fez-se presente dentro e fora dos círculos acadêmicos, fortemente moldada pela 'ideologia do progresso' e pela crença no ilimitado poder das ciências. Nesse sentido, ao homem caberia apenas aprender a rastrear os elementos causadores das enfermidades e neutralizá-los, conseguindo com isto viver mais e melhor. Durante bom tempo tal visão, de grande apelo triunfalista e evolutivo, moldou as percepções das doenças.

Contudo, como historiadores, somos desafiados a pensar nas doenças e nas possibilidades de explicá-las e tratá-las de forma não naturalizada, mas como construção plural de uma época determinada por especificidades e meios de ação que lhes são próprios e legítimos e, por conseguinte, socialmente aceitos no âmbito das crenças e das práticas dos indivíduos circunscritos a um dado contexto (Rosemberg, 1992, p.305; Cunningham, Williams, 1992, p.212-213).

Ainda de acordo com Rosemberg, é possível pensar o processo de 'enquadramento' (framing) das doenças com base em uma complexa interação entre o biológico e o social. Há na escrita desse autor uma preocupação patente com os intercâmbios entre o meio natural e as práticas sociais, evitando explicações que cairiam na dupla armadilha de considerar as doenças unicamente como 'dados naturais' ou como entidades meramente 'inventadas' pelos homens. Daí a necessidade de ampliar nosso olhar e tomar as doenças como objeto de estudos para pensar aspectos de ordem religiosa, moral, ações de Estado e relações mais gerais de poder no cerne do momento histórico escolhido para observação. Aliás, como prefere Rosemberg, as próprias concepções sobre os males humanos e as práticas médicas - como toda e qualquer ação humana - não poderiam ser pensadas fora de seu contexto sociocultural, a exemplo das ferramentas intelectuais e técnicas à disposição de médicos e demais curadores para diagnosticar e tratar determinada doença em dado período. Por essa razão, o autor considera tautológicas expressões como "história social da medicina" ou "construção social das doenças" (Rosemberg, 1992, p.307, 311). ${ }^{1}$ Com base nos argumentos do autor, neste artigo analiso de que modo os cirurgiões que atuaram em áreas coloniais na segunda metade do século XVIII, a exemplo de Dazille e Vieira de Carvalho, nomeavam e descreviam as doenças 'dos negros', balizados por um saber médico considerado válido em sua época.

Ludwik Fleck foi outro autor que buscou analisar historicamente as doenças, chamando a atenção para o fato de que a medicina é uma ciência que se afasta do trato dos fenômenos regulares, dado que a própria manifestação da doença pressupõe um descompasso no funcionamento regular do organismo, além de possuir significativo grau de variação. Debruçando-se sobre um estudo de caso - a gênese do conceito de sífilis -, o autor forjou o conceito de 'fato médico'. Segundo Fleck, o entendimento da sífilis como entidade nosológica passou por inúmeros caminhos ao longo do século XV. Identificada sobretudo como 'doença de Vênus' (e portadora de diversos nomes, como morbus gallico ou malfrancês, e scabies grossa), o que hoje chamamos de sífilis foi identificada juntamente com inúmeras outras doenças venéreas e dermatológicas (Fleck, 1986, p.47, 50), além de estar envolvida em uma série de explicações astrológicas, humorais e de caráter moral-religioso. 
Tais explicações, somadas a outras, informaram e moldaram as variadas formas de se definir o que hoje conhecemos como sífilis.

Ao seguir tal orientação teórica, um historiador que se debruçasse sobre as doenças do século XVIII incorreria em grande risco ao se valer da possibilidade de 'olhar para trás' e tentar associar determinadas doenças ou sintomas aos nossos conhecimentos atuais. ${ }^{2}$ Para evitar a tendência - anacrônica - de vermos como 'imprecisas' as considerações sobre as doenças em contextos diferentes do nosso, optei pelo uso da própria terminologia de Dazille para classificar as doenças que ele enfrentava como cirurgião na segunda metade do século XVIII.

\section{Autor e tradutor: saberes e trajetórias}

Em sua tradução da obra de Dazille, Antônio Vieira de Carvalho esboçou o seguinte agradecimento ao rei:

Felizmente meu destino me havia levado a ocupar nas Minas Gerais o emprego de Cirurgião-Mor do Regimento de Cavalaria, que guarnece a capital daquela Capitania; onde exercendo a par da minha profissão a Medicina prática, pude ver com os meus olhos, quanto a espécie humana sofre na inumerável multidão dos Negros, que ali transporta a escravidão, e o comércio. A mudança de clima; a diferença de tratamento; um trabalho contínuo, e desmedido; e até a fome raríssimas vezes interrompida; junto à triste consideração do seu penoso estado são outras tantas causas das singulares e gravíssimas enfermidades, a que é sujeita entre nós essa raça desaventurada de homens; e que fazendo-lhes a vida pesada, e adiantando-lhes a morte, levão à sepultura o melhor dos cabedais daquela e das outras Colônias da América Portuguesa (citado em Dazille, 1801, s.p.).

O texto original foi publicado em 1776, como produto das experiências do cirurgião francês; entre elas, sua atuação junto às tropas na ilha de São Domingos. Fruto ou não de encomenda direta, suas páginas refletiam frontalmente os anseios e reformas do Estado francês em seus domínios coloniais, que possuíam como um de seus principais vetores o regramento e o uso mais produtivo do braço escravo. A filiação a esse momento de reformas torna-se explícita com o oferecimento do tratado médico ao ministro das Colônias (Marquese, 2004, p.100).

Do mesmo modo, Vieira de Carvalho pede licença ao rei para dedicar-lhe seu esforço de tradução, igualmente publicada sob os auspícios régios na Tipografia do Arco do Cego, cerca de trinta anos após a publicação original.

A tipografia, criada em 1799, exerceu papel central na divulgação de saberes técnicocientíficos em terras lusas (Munteal Filho, 2001, p.492; Wegner, 2004, p.134). ${ }^{3}$ Essa iniciativa refletia a agenda ilustrada de produção e circulação do conhecimento útil, visando ao bem da humanidade e à multiplicação dos cabedais régios. Tal conexão entre o pensamento ilustrado luso-brasileiro e as vertentes utilitaristas do Iluminismo foi observada por Maria Odila da Silva Dias (1968), em trabalho clássico.

À frente da tipografia durante sua curta existência, frei Veloso promoveu a impressão e a divulgação de 83 obras, muitas delas traduções de originais escritos em francês e inglês. 
Entre os principais temas que saíram do prelo do Arco do Cego, encontram-se 'memórias' e tratados sobre o incremento da produção manufatureira, mineralógica e, sobretudo, da agricultura, em tentativa de adaptação da fisiocracia ao cenário colonial (Curto, 1999, p.48-49). Os estudos botânicos também ganharam destaque naquela casa, especialmente aqueles voltados para o melhor conhecimento da natureza colonial, além da instrução e instrumentalização de seus agentes, buscando ampliar as possibilidades de ganhos através da aclimatação de plantas exóticas e do melhor aproveitamento de certas culturas, como tabaco, chá e café, entre outras (Luna, Kury, 2012, p.6 e ss.; Numes, Brigola, 1999; Campos, Paes Leme, 2001, p.110-112).

A obra de Dazille encaixava-se perfeitamente nos interesses editoriais do Arco do Cego, devido a suas úteis observações sobre a administração da escravaria e o tratamento de suas enfermidades (Eugênio, 2000, p.160; Abreu, 2007, p.765). Desse modo, seria bastante plausível supor que a tradução do tratado francês tenha sido resultado de encomenda direta e mais uma faceta da empreitada levada a cabo por frei Veloso de publicar obras de sentido pragmático que, supostamente, possibilitariam maior eficácia na exploração das colônias lusas, já que, nesse momento, o Brasil assumia aí um papel central.

Aliás, autor e tradutor tinham trajetórias semelhantes: ambos haviam sido funcionários do Estado em áreas coloniais e formados no contexto da medicina ilustrada. ${ }^{4}$ Nesse sentido, devemos pensar a preocupação com a 'saúde dos povos' como questão-chave nas relações entre a medicina e as ações de Estado. De acordo com Foucault (2000, p.28), há uma relação direta entre as mudanças de paradigma do saber médico na segunda metade do século XVIII e o aumento do controle do Estado em torno das esferas coletivas. Resumindo, no contexto da Ilustração, as concepções sobre 'saúde dos povos', ideal de progresso e desenvolvimento científico eram indissociáveis (Abreu, 2007, p.763; Kury, 2004, p.110).

As análises de Marques, em pesquisa recente, convergem para esses olhares. A autora se vale de manuais médicos produzidos ou traduzidos por autores ilustrados luso-brasileiros na forma de 'avisos aos povos'. O conteúdo desses tratados trazia considerações sobre o tratamento de doenças, preocupações com a higiene, alimentação etc., que deveriam ser transmitidas por "pessoas caridosas" (padres, proprietários rurais, cirurgiões) para ecoar entre os grupos populares, em sua maioria impossibilitados de acessar diretamente os livros e a leitura. Esses 'avisos' - de caráter normatizador, ao afirmar o saber médico oficial obtiveram significativa ressonância, ganhando diversas edições, várias delas transportadas para colônias lusas como o Brasil (p.9).

Outro vetor que nos faz entender a iniciativa de tradução e publicação do tratado médico francês é o desenvolvimento de uma "lógica de redes", que fomentava a circulação de informações e promovia intenso diálogo, ainda que assimétrico, entre os impérios coloniais luso, francês e inglês (Kury, 2004, p.114; Domingues, 2001, p.823-838). Segundo Lorelai Kury (2004, p.115), "as elites intelectuais luso-brasileiras tentaram conhecer as demais experiências coloniais e participar do circuito internacional de circulação de textos científicos".

No esteio dessa mentalidade científica e trocas intelectuais, a obra de Dazille e a tradução de Vieira de Carvalho configuram-se como exemplos bem distantes do extraordinário. Um breve levantamento nos coloca diante de uma quantidade expressiva de títulos que indicam 
as preocupações de médicos e cirurgiões com os centros de produção escravista dos impérios coloniais francês e inglês, alguns deles chegando também aos leitores de língua portuguesa mediante traduções. Assim, é possível elencar, tomando como exemplo o caso inglês, entre outros tratados, An essay on the treatment and conversion of african slaves (1784); A treatise on the fevers of Jamaica (1791); Observations on the diseases of the army in Jamaica (1791); Medicine advice to the inhabitants of warm climates (1790), sendo as últimas três obras escritas por cirurgiões e médicos que, como Dazille e Vieira de Carvalho, serviram às tropas régias em áreas coloniais britânicas.

No ano da publicação do tratado de Dazille, a Tipografia do Arco do Cego tirou do prelo outra tradução - feita pelo próprio frei Veloso - que igualmente refletia a preocupação com o conhecimento médico e terapêutico de cenários coloniais comparáveis ao Brasil, voltada, dessa vez, para o Suriname. Refiro-me à Collecção de memorias sobre a Quassia amarga... (Veloso, 1801). Novamente deparamo-nos com a circulação de informações entre médicos, administradores e estudiosos da natureza colonial.

Creio poder pensar tais obras como um gênero da literatura médica que promoveu aprendizados e trocas entre os diversos agentes desses impérios coloniais, tornando possível a reunião de uma série de conteúdos comuns que faziam parte das premissas da medicina ilustrada. Das preocupações de Dazille e Vieira de Carvalho com mais cuidado da escravaria nas colônias de seus soberanos emergiam observações acerca das especificidades da natureza, do clima e das doenças nos trópicos; de como, muitas vezes, essa mesma natureza vista como produtora de doenças e perigos era pródiga no fornecimento de plantas terapêuticas; do cuidado com a 'saúde dos povos' - com especial destaque, como já mencionado, para os cativos; da relação entre um controle eficaz das áreas coloniais e o fortalecimento de suas metrópoles, sob o prisma do 'utilitarismo' das Luzes; da revalorização do legado hipocrático-galênico através do neo-hipocratismo; da ênfase na experiência e na sofisticação dos estudos anatômicos para melhor conhecimento das doenças e de seu tratamento (Jordanova, Porter, 1997; Calafate, 1994; Porter, 1999). ${ }^{5}$

A análise do testamento do cirurgião Vieira de Carvalho, falecido em 1818, dá mostras, mais uma vez, dessa intensa circulação de conhecimentos. O cirurgião-mor possuía uma biblioteca com 127 títulos. Carvalho era um leitor atualizado, cosmopolita e ávido por informações sobre seu campo de atuação profissional. A maioria de seus livros era composta por tratados de cirurgia, anatomia e história natural de autores ingleses, franceses e 'portugueses estrangeirados', de importância crucial para o desenvolvimento da medicina ilustrada em Portugal, tais como Tissot, Ribeiro Sanches, Vandelli e Vigier. Carvalho possuía ainda, em sua biblioteca, dois tratados de história natural de Lineu, entre outras obras (Inventário..., 1905, p.706-709). Com isso, o cirurgião-mor, aquartelado em Vila Rica, alinhava-se aos princípios intelectuais almejados pela reforma do saber médico luso, baseada na valorização da experiência, nos estudos de anatomia e cirurgia e no diálogo direto com as teorias científicas mecanicistas (Abreu, 2007, p.82-83; Ribeiro, 2003). Aliás, o cirurgião/tradutor deve ter contribuído de forma direta para a difusão desse novo tipo de saber, visto que atuava também como lente de anatomia, cirurgia e operações no hospital militar de Vila Rica.

Como a atual historiografia das ciências tem mostrado, esses saberes, produzidos principalmente pelos homens de ciências ingleses e franceses que circulavam por seus 
domínios coloniais, eram fruto de contatos, trocas e aprendizados que envolviam diversos agentes, como soldados, escravos e populações autóctones, ainda que tais conhecimentos e práticas fossem, muitas vezes, deliberadamente 'apagados' na produção desses tratados (Harrison, 2005, p.58-61; Pratt, 1999, p.30-32; Raj, 2007, p.7-26).

Do mesmo modo, os autores luso-brasileiros, como ocorreu também em outras áreas coloniais, não receberam passivamente as inovações desses centros hegemônicos francoingleses de produção científica: eles fizeram escolhas, filtraram e reelaboraram o conteúdo das obras que traduziram ou usaram como referências para seus próprios escritos. Essa produção científica, em alguns casos, também chegou a circular nas metrópoles coloniais (Kury, 2004, p.113 e ss.; Gavroglu et al., 2008, p.156-160).

Nesse sentido, ancorado em sua experiência em terras coloniais e em conhecimento teórico, Vieira de Carvalho não se contentou em ser mero tradutor da obra de Dazille. As inclusões e modificações nos textos traduzidos, contudo, não seriam apenas fruto do ímpeto pessoal do cirurgião-mor das Minas. Os padrões de produção e circulação de conhecimentos científicos do século XVIII 'autorizavam' a inclusão de referências e atualizações bibliográficas; a supressão e/ou a reestruturação da disposição dos capítulos do texto original; os comentários e as inclusões de trechos de tratados congêneres (excertos) e a produção de notas de rodapé, nas quais se expunham as considerações e as intenções do tradutor, em conformidade com variados interesses locais, para melhor recepção da obra traduzida (Kury, 2007, p.145; Luna, Kury, 2012, p.2 e ss.; Gavroglu et al., 2008, p.166).

Assim, ao longo das páginas de Observações sobre a saúde dos negros, Carvalho introduziu notas explicativas - oito, na verdade - nas quais ambientava melhor seu leitor ao contexto das Gerais, ao descrever os nomes locais de plantas e doenças, mostrando que, comparados às descrições de Dazille, os escravos nas Minas pareciam ser mais bem alimentados (Dazille, 1801, p.29). O autor propunha ainda a substituição de ingredientes em fórmulas, como a sugestão da água cordial em lugar da água de Scabiosa, "segundo o permitir o País" (p.64).

Após essas discussões preliminares, proponho analisar de que modo as doenças 'dos negros' eram nomeadas e concebidas em fins do século XVIII e começo do XIX, informado fundamentalmente pela tradução do tratado de Dazille e pela crença na existência de irresistíveis pontos de convergência a unir a ilha francesa de São Domingos às possessões lusas das Gerais, graças à "analogia de muitas circunstâncias físicas e morais", conforme acreditava seu tradutor (s.p).

\section{Dazille e as enfermidades 'dos negros'}

Logo no início de seu tratado médico, Dazille preocupa-se em escrever uma "Introdução" de 19 páginas, visando alertar seu leitor sobre as causas gerais de aquisição das doenças (ainda não caracterizadas em detalhes nessa altura da obra). Podemos perceber três fatores cruciais que alteravam a saúde dos negros: as características naturais das áreas coloniais; suas condições de vida e trabalho e determinados traços, vistos como inatos, de seus corpos e personalidades.

A natureza peculiar das 'zonas tórridas' preocupava em especial o cirurgião francês, tanto que, em sua obra, há considerável espaço para argumentos que associavam os 
diferentes climas e ambientes à ocorrência de doenças. Sobre tal caráter insalubre da natureza colonial Dazille (1801, p.17) informa:

O professor, chegando a uma Colônia, deve examinar a situação do país, os lugares elevados, as lagoas, suas distâncias das habitações, ou das cidades, os ventos que reinam mais ordinariamente, as qualidades das águas, o gênero da vida dos habitantes, seus costumes, seus alimentos, seus trabalhos, enfim o seu modo de se vestir...

Estes primeiros conhecimentos o conduzem ao estado daquelas cousas que tendem de mais perto aos homens, que nele tem de socorrer, tais como seus temperamentos, e tudo, o que lhes pode ocasionar diferenças; ele indaga, quais são os humores predominantes, que os constituem e caracterizam em particular.

Aqui já é possível notar o peso das concepções hipocráticas acerca da influência dos fatores naturais na alteração dos humores.

A despeito de sua preocupação com as enfermidades 'dos negros', percebemos o cuidado em lançar luz sobre os perigos que essa nova natureza reservava para os colonos europeus. As doenças provocadas sob o regime de clima e ambiente hostis eram especialmente implacáveis com os recém-chegados do Velho Mundo: "Os grandes calores da Zona tórrida, que com pouco propósito se tem considerado como a causa primeira das enfermidades dos seus habitantes, e, principalmente, daquelas que aí experimentam os novatos vindos da Europa, não fazem mais do que desenvolver essa causa, e dar-lhes mais, ou menos atividade" (Dazille, 1801, p.19).

Cerca de 12 anos após a tradução do tratado de Dazille, Luís Antonio de Oliveira Mendes publicou seu Discurso sobre as doenças dos pretos tirados da África, sob o patrocínio da Academia Real das Ciências de Lisboa. Nele, há considerações sobre o fato de que a mudança forçada da natureza à qual os negros estavam acostumados em terras africanas gerava ou agravava enfermidades, quando de sua vinda para o Brasil. Uma vez mais, a natureza diferente impunhase como elemento de grave importância para o abalo da saúde:

O certo é que os povos africanos em os países de sua habitação, e natalício são muito menos atacados, do que em qualquer outra parte, e por isso já dissemos, que no seu tanto logra boa saúde. Isto se deve ao ar, a que estão 'acostumados', e aonde nasceram, aos seus constantes e certos alimentos, e as mesmas tais e quais águas, de que usam e 'a que estão habituados' (Mendes, 1987, p.28; grifos meus).

É possível inferir, com base nas fontes citadas, algumas verdades do discurso médico ilustrado acerca dos entroncamentos entre as doenças, a natureza colonial e os indivíduos envolvidos nessa empresa. Primeiramente nos chama a atenção o conjunto de variáveis envolvidas nas descrições da natureza das 'zonas tórridas': temperatura, tipos de vento, abastecimento e qualidade das águas, topografia, latitude, movimentos e/ou posição dos astros. Todos esses aspectos deveriam ser observados com acuidade e articulados para o conhecimento das doenças e o melhor tratamento dos doentes.

Nesse ponto é inegável o peso da tradição hipocrático-galênica no reconhecimento de um vínculo direto entre ambiente e doença. Aliás, a própria preocupação com a observação detalhada das particularidades de cada clima e lugar está fortemente presente nos textos escritos ou atribuídos ao médico "grego" (Cairus, 2005, p.94-95). No curso do século XVIII, 
especialmente em sua segunda metade, o legado hipocrático ganhou novo fôlego, e o neohipocratismo agregou elementos oriundos dos novos métodos empiristas e da filosofia sensualista (Kury, 2007, p.157-166; Hannaway, 1997, p.302-306). Como nos ensina Lorelai Kury, no final do século XVIII e início do XIX, houve uma tendência ao enfraquecimento do olhar generalizante e detrator da natureza colonial como 'zona tórrida'. Entretanto, "no que concerne às teorias médicas, verifica-se maior persistência das considerações tradicionais sobre os climas tropicais" (Kury, 2007, p.157). ${ }^{6}$ As páginas do tratado de Dazille, decerto, nos dão mostras dessa faceta detratora.

Para muito além das novas enfermidades, mesmo as doenças já conhecidas, uma vez desenvolvendo-se em áreas coloniais, adquiriam maior virulência e desafiavam os curadores oriundos do Velho Mundo. A gonorreia, por exemplo, vista e tratada na Europa, "é ordinariamente a de menor consequência", coisa que não acontecia nos "países quentes", pois "o humor espalhando-se com mais abundância no prepúcio e glande, causa aí uma inflamação muito viva" (Dazille, 1801, p.125).

Aliás, essa preocupação dos médicos e cirurgiões em lançar um olhar atento sobre as relações entre as especificidades naturais e o quadro nosológico de um determinado local, ou ainda de que modo naturezas diferentes forjavam corpos diferentes, possuía longa data, nos remetendo, uma vez mais, ao legado hipocrático-galênico. Nas páginas do Ares, águas e lugares, um dos tratados de maior ressonância do corpus hippocraticum, o médico 'grego' adverte sobre a necessidade crucial de um pormenorizado conhecimento das características das novas áreas de atuação dos indivíduos responsáveis pelas curas. Sofisticando seu argumento, Hipócrates enfatizava de que modo as variações climáticas, a influência dos astros, a posição de uma área "que se volta para o sol que se ergue" ou "para o sol se pondo", entre outros aspectos, determinavam a maior ou menor salubridade de um "lugar" e as diferentes enfermidades que atingiam esses diferentes espaços (Cairus, 2005, p.94-99).

No contexto da produção do tratado de Dazille, o termo aclimatação e a elaboração de seus significados vão ganhando corpo, fortemente influenciados pelas concepções neohipocráticas e pelas vertentes utilitaristas da Ilustração, juntamente com várias outras formulações visando ao melhor aproveitamento e administração das áreas coloniais. A busca por descrições cada vez mais específicas e a ampliação do olhar sobre os aspectos naturais das áreas de atuação desses cirurgiões e médicos - associadas aos modos de vida, habitação e condições sanitárias - ganhariam grande destaque, sendo o que conhecemos como 'geografia médica' uma das principais facetas da medicina neo-hipocrática. Somavase a isso a preocupação em monitorar e compilar dados meteorológicos coletados com frequência e elaborar sistematizações antes inexistentes, a forjar e difundir um tipo de fazer ciência cada vez mais balizado pela valorização da experiência e pela construção e institucionalização de 'métodos', sem contar com a reorientação de explicações de estofo hipocrático acerca da relação ambiente/doenças (Hannaway, 1997, p.300; Jordanova, Porter, 1997, p.128 e ss.; Kury, 2007, p.143-144, 161-163).

Para Dazille, um dos maiores perigos naturais que se poderiam encontrar em áreas coloniais, e especialmente em São Domingos, eram as 'águas estagnadas'. Nesse trecho da obra percebemos seu esforço em sublinhar o argumento geral da insalubridade e dos riscos de ocupar as 'zonas tórridas'. Segundo o autor: 
Tendo passado as estações chuvosas, as águas encharcadas se corrompem, e ocasionam pela sua putrefação, e de uma infinita quantidade de insetos, e pequenos animais, emanações que se espalham no ar, e daí passam aos bofes pela respiração, e levam aos nossos humores o gérmen das enfermidades, que afligem os habitantes dos lugares circunvizinhos...

As lagoas, em cujo maior número as águas corruptas espalham um cheiro muito mau, servem de covil a esta multidão de pequenos animais cujos miasmas são trazidos pelo vento a muitos quartéis da Ilha, onde eles causam enfermidades mais ou menos graves (Dazille, 1801, p.20-21).

Novamente o cirurgião francês reforça a crença no desequilíbrio dos humores como um dos grandes responsáveis pela produção das enfermidades, sendo essa concepção atualizada pela 'teoria dos miasmas'. Podemos inferir que Dazille estabelecia relação causal entre a noção de miasmas e a antiga tradição hipocrático-galênica dos humores, como fica patente na ênfase dos perigos provocados pelas 'águas estagnadas'. Na segunda metade do século XVIII, somou-se às considerações hipocráticas a noção correlata de miasmas: emanações atmosféricas provenientes de pântanos, águas estagnadas, solos e da decomposição de animais e vegetais, que poderiam percorrer longos caminhos até contaminar os seres humanos. Desse modo, fortalecia-se ainda mais a relação entre o desequilíbrio dos humores e o meio natural (Kury, 1990, p.74-79; Hannaway, 1997, p.295).

Enfim, outro vetor da teoria humoral que parece ter exercido grande influência nas considerações acerca das enfermidades dos negros de Dazille (1801) seria a ideia de que, além do desequilíbrio dos humores, o corpo enfermo também poderia produzir outras excrescências e "fluidos", a exemplo do muco nasal, como produto das doenças (Nutton, 1997, p.283). Ao que parece, baseando-se nesse tipo de concepção, Dazille chama a atenção em várias partes do seu trabalho para a existência do "humor morbífico" no organismo de seus pacientes (p.81). Posteriormente, ao tratar das "enfermidades venéreas", aparecem ainda na pena do cirurgião francês outras variações nos humores, apresentadas como oriundas das inflamações venéreas, como o "humor virulento"; o "humor glutinoso" e o "humor da gonorreia" (p.106, 113, 131).

Em segundo lugar, somando-se à natureza colonial, aparecia na escrita de Dazille (1801), como explicação para as causas das doenças que fustigavam os negros, o que poderíamos chamar de 'estilo de vida'. O cirurgião francês buscava, de modo deliberado, fazer distinção entre "as causas das enfermidades comuns a todos os homens nas Colônias" que, como vimos, estavam fortemente ligadas aos fatores climáticos e ambientais, ainda que sua intensidade fosse bastante variável, e as "que são particulares dos negros" (p.27), estas, em grande medida, explicáveis por suas condições de vida e trabalho como escravos. Aliás, é possível observar na pena do autor uma relação imediata entre 'negro' e 'escravo', termos que aparecem praticamente intercambiáveis no curso das páginas do tratado traduzido.

A má alimentação, as vestimentas inadequadas, as rotas que proporcionavam enfermidades provocadas pela "passagem repentina do calor para o frio" (Dazille, 1801, p.30) esse regime de trabalho prolongado e rigoroso era descrito, não raro, na "Introdução" do tratado médico, com certo tom de denúncia. 
As más condições de nutrição foram sublinhadas por Dazille (1801, p.29) de modo especial, traçando inclusive uma comparação entre a dieta das tropas e aquela 'dos negros, que pesava gravemente em suas condições de saúde, uma vez que estavam todos sob o imperativo do mesmo tipo de 'clima':

Com tudo, os Negros morrem quase todos nestas Colônias de enfermidades podres, e verminosas, de disenterias ou de supurações no bofe; e raro, que eles sejam atacados de enfermidades puramente inflamatórias.

A primeira causa destas diferentes moléstias dos Negros, provém do seu alimento, que consiste geralmente em raiz de mandioca grosseiramente pisada, feita em bolo, e muitas vezes mal cozido.

Por outro lado, sua vivência nos domínios além-mar proporcionou-lhe um olhar mais matizado em torno das multifacetadas formas de tratamento dos cativos. Fruto desse olhar é sua sensibilidade em distinguir os "negros domésticos" dos demais escravos, sendo os primeiros apontados como menos propensos a determinadas enfermidades, pois, em sua perspectiva, "vivem quase como os Brancos" (Dazille, 1801, p.76).

Por fim, Dazille (1801, p.31) volta-se para as características 'inatas' dos negros:

Nascidos, e chegados a uma idade avançada, sem princípios, é muito difícil inspirarlhes costumes; eles são também muito inclinados a libertinagem; a extrema preguiça é igualmente um dos seus vícios dominantes ...

A libertinagem é muito mais perigosa nos Negros, que para a satisfazer, vão muitas vezes procurar ao longe, durante a noite, o objeto de seus desejos ... Outra inclinação que não tende menos a destruí-los é a que eles têm aos liquores fortes.

A "libertinagem", tratada como um dos traços 'naturais' mais característicos dos negros, será lembrada de modo mais recorrente na parte da obra dedicada às doenças venéreas. Para além desses "impulsos" e "inclinações", havia igualmente a preocupação em explicitar a existência de diferenças anatômicas e fisiológicas, como "a secura, e aridez das fibras dos Negros" (Dazille, 1801, p.33), bem como a menor disposição de seus humores às inflamações (p.56). O fato é que Dazille era informado pela crença coeva de que os organismos de negros e brancos funcionavam, em grande medida, de modo distinto, tanto que, em uma das notas de seu tratado, o autor fez questão de frisar: "Eu me proponho a entrar em maior explicação sobre esta matéria nas minhas observações sobre as enfermidades dos Brancos nas Côlonias" (p.18). Contudo, não foi possível encontrar até o momento nenhuma referência acerca da redação dessa aparente nova obra do cirurgião francês.

O autor do Discurso sobre as doenças dos pretos também acreditava na existência de diferenças entre os corpos e as 'inclinações' de negros e brancos. Ao analisar as 'doenças crônicas' que assolavam os africanos trazidos para o Brasil como cativos, Mendes (1987, p.31) sublinha o banzo como um dos grandes males locais. Em sua explicação, é patente a especificidade deste 'temperamento natural' dos negros: "[banzo] É uma paixão de alma, a que se entregam, que só é extinta com a morte: por isso disse, que os pretos africanos eram extremosos, fiéis, resolutos, constantíssimos, e susceptíveis no último extremo do amor e do ódio". 
Feitas as considerações iniciais sobre as causas mais gerais que alteravam o estado de saúde dos negros, o tratado passa a ganhar ares mais específicos. Nessa altura da obra, as doenças começam a ser nomeadas e descritas em seus pormenores.

Na tradução da obra de Dazille são apresentadas sete enfermidades que afligiam em especial a população negra de São Domingos, transformadas em subitens pontuais que sucedem à supracitada "Introdução", sendo eles: "febres podres", "diarreia e disenteria", "enfermidades verminosas", "enfermidades do peito", "supuração do bofe", "enfermidades venéreas" e "bobas". Embora não constitua uma seção em separado, somava-se a essas doenças o "escorbuto", várias vezes mencionado ao longo do tratado como uma doença grave e de enorme incidência entre a população negra de São Domingos (Dazille, 1801).

Cabe aqui uma ressalva: o peso do tráfico nas condições de saúde dos negros praticamente não é considerado na obra traduzida. Uma das únicas menções às desventuras da travessia é referida quando se lê a respeito do escorbuto. Nessa matéria, o cirurgião francês novamente fazia eco ao pensamento médico de seu tempo, entrelaçando de modo imediato essa doença ao tráfico negreiro: “A situação dos Negros a bordo dos navios é das mais terríveis. Acomodam-se mais ordinariamente na cobertura dele, de maneira que ficam tão juntos, que entre eles não resta espaço algum; nenhuma, ou quase nenhuma possibilidade para a renovação de ar em climas tão ardentes" (Dazille, 1801, p.66). ${ }^{7}$

É possível inferir que a pacífica aceitação do escorbuto como 'doença africana' possa ter motivado Dazille a diluir as considerações a seu respeito ao longo do tratado. Assim, em diversos momentos, o escorbuto é retomado, ora por meio da comparação de seu curso em "três estágios" com o de outras doenças, como se fez com a "supuração do bofe"; ora para tratar dos perigos do escorbuto associado às doenças venéreas, aproveitando para sofisticar as descrições de seus graves sintomas, por vezes similares aos de outras enfermidades, o que algumas vezes confundia os curadores menos experientes, como fez questão de sublinhar - e não de forma inocente - o cirurgião francês (Dazille, 1801, p.108-109).

Ao discorrer sobre cada uma dessas doenças, é possível perceber uma ordenação canônica na escrita do cirurgião francês que, uma vez mais, seguia a lógica de produção dos tratados médicos coevos. Desse modo, há uma regra na apresentação das doenças: em primeiro lugar, eram nomeadas e brevemente descritas, em seguida, definiam-se seus sintomas em minuciosos detalhes, sendo arroladas suas causas e, por fim, os tratamentos necessários para recobrar a saúde dos pacientes.

Ao tratar "das febres podres", Dazille (1801, p.34) fornece a seguinte descrição:

A Febre podre é uma enfermidade na qual os humores tendem à putrefação; ela se anuncia ordinariamente muitos dias antes da sua invasão pelo mau estado das primeiras vias ...

A febre sobrevém, e começa as mais das vezes por um calefrio considerável, seguido de um calor mordicante, durante o qual o pulso se desenvolve mais, ou menos; sentem-se sobressaltos nos tendões, a cabeça se perturba, o rosto se faz vermelho, o ventre se meteoriza, as urinas são avermelhadas ou cor de tijolo...

Mais adiante, ao examinar a "supuração do bofe", o autor igualmente descreve com riqueza de detalhes de que modo essa doença deveria ser observada pelos oficiais de saúde nas colônias: 
Os sinais, que anunciam a supuração no bofe em consequência da falsa peripneumonia, são, $1^{\circ}$ a ausência dos que deveriam anunciar a resolução desta enfermidade; $2^{\circ}$ a falta das crises; $3^{\circ}$ alguns calafrios irregulares no fim do termo ordinário; $4^{\circ} \mathrm{o}$ embaraço na respiração; 5 o enfim a continuação da febre, que toma o caráter de febre lenta (Dazille, 1801, p.88).

Esses dois trechos são reveladores da grande preocupação com a descrição dos sintomas para descortinar as doenças, sobretudo no decorrer da segunda metade do século XVIII. Ao examinar seus pacientes, Dazille atém-se à observação da cor e do cheiro da urina; às marcas externas do corpo; à ocorrência de calafrios e suores noturnos; aos diferentes tipos de febre; à cor da pele... Segundo Foucault, desenvolve-se na prática desses médicos e cirurgiões uma atitude que ganhará progressivamente ares protocolares e normativos: o exame clínico. A descrição pormenorizada dos sintomas, bem como a organização de uma 'geografia médica' também para as doenças e os locais do corpo enfermo em que elas se manifestavam, passa a moldar cada vez mais os olhares e as ações dos curadores oficiais, tais como Dazille (Foucault, 2004, p.117-119; Jordanova, Porter, 1997, p.130).

Para tanto, era preciso esquadrinhar os corpos doentes em quantidade e frequência. Copiosas vezes. O desenvolvimento da observação clínica fazia-se no espaço hospitalar, cada vez mais dominado e regrado pelos médicos (Foucault, 2004, p.119-123). Não por mero acaso, tanto Dazille quanto seu tradutor atuaram diretamente nos hospitais coloniais de São Domingos e Minas Gerais, onde tiveram a oportunidade de observar, quantificar e descrever as manifestações das doenças que grassavam em seus pacientes.

Tais mudanças - paulatinas e sinuosas - no modo de olhar as doenças, possuem vínculos diretos com a maior valorização da experiência. Como argumenta Paolo Rossi (2001, p.252-258), o desenvolvimento de vários segmentos das ciências na Europa, nos quais a medicina estava inserida, é marcado pela ênfase nos experimentos e no conhecimento prático (não raro, desenvolvido por oficiais mecânicos) e pela crescente afirmação da teoria mecanicista - palavra de significado polivalente, mas fortemente relacionada à crença na existência de leis regulares que permitiam a explicação de fenômenos considerados universais (Calafate, 1994, p.37-38). Essa atitude intelectual de valorização da experiência ganha novo fôlego e diferentes contornos no decorrer do século XVIII. Havia, nesse período, uma progressiva preocupação com a produção de dados estatísticos, tabelas, cruzamento de informações que, antes de se restringir ao universo médico, se vinculava de modo amplo e crucial ao "fazer ciência" do período estudado, além de possuir funções didáticas e legitimadoras desse tipo de saber (Kury, 2007, p.166-175).

Dazille e Carvalho, ambos cirurgiões e, portanto, oficiais mecânicos da medicina, afirmaram a legitimidade de um conhecimento das doenças fortemente ancorado na experiência prática e teceram críticas aos médicos que se utilizavam exclusivamente do conhecimento livresco e da 'tradição'. Em vários trechos da obra estudada, podemos encontrar construções textuais como "pela experiência comprovada" (Dazille, 1801, p.16); "a observação mostra" (p.57); "a experiência demonstra" (p.97).

Nesse momento de mudanças na prática médica, igualmente verifica-se, no decorrer da segunda metade do século XVIII, uma crescente atenção aos estudos anatômicos, vistos como um dos mecanismos mais eficazes para auxiliar na identificação das doenças. Ocorre 
assim um imbricamento de conhecimento e busca dos sintomas por meio do exame clínico, e o desenvolvimento cada vez mais sofisticado da anatomia patológica (Foucault, 2004, p.138). Para tanto, faziam-se necessários o incremento das dissecações de cadáveres e a maior aproximação entre a medicina e a prática da cirurgia (Weiner, Sauter, 2003, p.27-28; Abreu, 2007, p.80-86).

Decerto esse tipo de saber médico formou os cirurgiões Dazille e Vieira de Carvalho que, cientes da importância da investigação do interior dos corpos para o melhor conhecimento e descrição das doenças, sentiram-se motivados a abrir os cadáveres de seus pacientes perdidos nos hospitais régios onde atuaram. Ao se debruçar sobre as "enfermidades verminosas", Dazille (1801, p.73) expõe sua experiência, deixando, ao que parece, certo exagero expresso nestas linhas: "Nós temos já observado, que, pela abertura de 'todos' os cadáveres dos Negros mortos de enfermidades, qualquer que seja, em muitas Colônias, se acham os intestinos cheios de lombrigas, que devem sua existência à comida insípida, não fermentada, e mucosa, a que eles são limitados" (grifo meu).

De forma análoga, o cirurgião-mor de Vila Rica fez questão de expor sua experiência na arte da dissecação. Em uma de suas notas, narrou a abertura do corpo de um negro, de propriedade de José de Vasconcelos - capitão do seu regimento - no ano de 1785, morto em "consequência de uma dor no ventre". No momento da abertura do cadáver, mais uma vez, deparava-se com doença comum entre os cativos: "o estômago e todo o canal intestinal achava-se com inúmeras lombrigas" (Dazille, 1801, p.74).

Além da menção às lombrigas, encontramos na obra traduzida uma preocupação patente com outras enfermidades que afetavam de modo assíduo o aparelho digestivo dos negros nas colônias. Na seção de seu tratado intitulada "Da diarreia, e da disenteria dos Negros", Dazille retoma suas considerações a respeito do "modo de viver" dos negros e do "abatimento frequente" a que estavam submetidos, não esquecendo, uma vez mais, de enfatizar suas condições precárias de alimentação. Desse modo, consoante com a percepção coeva da 'evolução' das doenças, o estado de saúde de seus pacientes se agravava por conta da má alimentação, fazendo com que "pela maior parte dela [a "diarreia"] degenera em disenteria" (Dazille, 1801, p.54), o que tornava o tratamento mais custoso, de acordo com o cirurgião francês.

Para evitar tal sorte de enfermidades e recuperar os cativos das péssimas condições da travessia - causadora principalmente do escorbuto, como já dito -, Dazille (1801, p.70) sugeriu a criação de um "Hospital de Negros, chegados de viagem nos quartéis mais elevados das Colônias" e, sobretudo, que fossem mais bem alimentados: "Depois do ar, a escolha dos alimentos é a cousa mais importante. Todas as substâncias vegetais, e frescas do uso das nossas cozinhas convêm nesta circunstância, mais principalmente o mastruço".

Os 'males de Vênus' habitaram igualmente as preocupações do cirurgião francês. A seção intitulada "enfermidades venéreas" possui o maior número de páginas dedicadas a um tipo de doença específica - nada menos que setenta. Nelas, Dazille (1801, p.106) refaz o argumento da maior propensão dos negros a tais achaques, "sobretudo pelo excesso de sua libertinagem" e, uma vez mais, sublinha os perigos de se viver nas 'zonas tórridas'. O clima quente das colônias potencializava a virulência das doenças sexuais, tornando-as mais fortes e imper- 
tinentes quando comparadas às suas ocorrências na Europa, pois "nos países muito quentes o vírus venéreo é muito mais ativo, e seus acidentes mais funestos" (p.153).

Para melhor pontuar sua definição das doenças venéreas e tendo em vista que, a despeito de sua variedade, o tipo de tratamento praticamente se resumia à administração do mercúrio, o autor explicita sua escolha de como tratar o assunto:

Eu não tratarei de cada sintoma venéreo particular ... Eu referirei somente, em que casos, e de que modo tenho feito uso destes meios: falarei em particular da gonorreia, tão comum nos negros, dos acidentes inflamatórios, que a acompanham muitas vezes, e de uma enfermidade venérea, que lhes é própria, conhecida debaixo do nome de 'pian' (Dazille, 1801, p.99-100).

Em mais uma de suas notas, o cirurgião-mor e tradutor da obra francesa esclarece que o "pian" no Brasil, e "particularmente em Minas", é conhecido como "bobas" (Dazille, 1801). Acerca da gonorreia, Dazille adverte que existe um sem-número de variações, "em razão da maior, ou menor extensão, e violência da inflamação, que a tem produzido". Assim, dependendo da qualidade e força do "humor virulento", poderia ser "benigna ou maligna"; "seca ou úmida"; "virulenta"; "caída no escroto". Para o autor, as doenças venéreas ainda poderiam se desdobrar em outros "acidentes", a exemplo da "oftalmia venérea". Uma vez mais, deparamo-nos aqui com a percepção de que determinados achaques acabavam "degenerando" em outros, em função de seu agravamento (Dazille, 1801).

Ao mencionar as "bobas", Dazille as define como uma enfermidade "particular aos negros", descrevendo a seguir seus sintomas e a capacidade destrutiva das inflamações em várias partes do corpo, "mas principalmente nas da geração", que produziam ulcerações e "carias" e, dependendo de sua gravidade, levavam o paciente a óbito. Em suas considerações acerca das doenças venéreas, percebi novamente o peso do neo-hipocratismo na pena do cirurgião francês. Após expor o papel do clima quente e da "natureza" dos negros, o autor observava ainda que essas pessoas seriam mais suscetíveis aos "acidentes de Vênus" em função de sua alimentação e do tipo de trabalho que exerciam, o que nos remete à ampla concepção hipocrática de 'dieta': "É de presumir, que o vírus venéreo exerce principalmente sua atividade sobre os corpos mal nutridos, fatigados, enervados, pois que ele produz acidentes mais graves, mais mortíferos, e menos susceptíveis de cura" (Dazille, 1801, p.153).

Nunca é demais lembrar que a prática sexual deveria ser regrada, não apenas para livrar os indivíduos de enfermidades venéreas. O modo de cirurgiões como Dazille conceberem as doenças - orientados por fatores multicausais e, em geral, fortemente conectados situava a atividade sexual como parte de um gradiente mais amplo que poderia interferir de modo decisivo na saúde ou na eficácia da cura de seus pacientes.

Enfim, ainda que devido às opções e limites deste artigo eu tenha preferido trabalhar com as considerações de Dazille acerca das doenças e os modos como assaltavam os corpos 'dos negros', talvez seja relevante um breve olhar sobre suas estratégias de tratamento enquanto atuou em São Domingos, abordagem que pode suscitar pesquisas vindouras.

À primeira vista, me chamou atenção, juntamente com as pesquisas de Roy Porter, a existência de certa dissonância entre as novas e distintas formas de descrever e identificar as doenças por parte da 'medicina das luzes', e as formas de tratar os doentes, - marcadas 
por fortes permanências. ${ }^{8}$ Assim, mesmo valorizando os "éteres" como "remédio precioso tão poucas vezes empregado na medicina" (Dazille, 1801, p.10) e propagandeando os avanços da "química moderna", talvez não seja exagerado afirmar que a maioria das receitas divulgadas pelo cirurgião francês incluía componentes oriundos do reino vegetal, muitos deles já bastante conhecidos e presentes em farmacopeias anteriores às mudanças no saber médico, verificadas sobretudo no decorrer da segunda metade do século XVIII.

Ao curar a "febre podre", o cirurgião francês não se furtou em continuar a receitar sangrias - ainda que mencionasse sua "reserva", em função do "empobrecimento dos líquidos" dos negros e das diferenças climáticas entre a Europa e as colônias - além da "ypecucuanha" [sic] como vomitório (Dazille, 1801, p.38). Cerca de sessenta anos antes, Gomes Ferreira usara com grande frequência a supracitada planta, ressaltando, como Dazille, suas propriedades eméticas, embora o fizesse especialmente para curar os doentes de "cursos" (Ferreira, 2002, p.629-630).

Encontrei ainda, no receituário do cirurgião francês, cânfora, limão, laranja, cravo, melissa, maná, entre outros ingredientes bastante presentes em tratados médicos da primeira metade do século XVIII (e mesmo antes) e no "Regimento dos preços por que os boticários do Brasil hão de vender os medicamentos", datado de 1742 (Regimento..., 1742). Tal observação nos oferece pistas sobre a permanência de determinadas formas de tratamento, que continuariam vigentes ao longo de boa parte do século XIX (Figueiredo, 2002; Pimenta, 2003, 312-315). Porém, como já dito, meu argumento está longe de ter caráter conclusivo, uma vez que carece de maior embasamento na pesquisa e do cotejo dos produtos receitados como remédio nos diferentes tratados médicos, além da análise de seus usos e das doenças a que eram destinados. Instigante e complexo labirinto que habita as páginas escritas pelos cirurgiões do século XVIII.

\section{Considerações finais}

Designado para atuar na colônia francesa de São Domingos, Dazille, "pelo amor e fidelidade ao seu rei", viu-se obrigado a escrever as páginas aqui analisadas. Acreditava-se produtor de conhecimento útil para a "humanidade" e para a salvaguarda da prosperidade de seu país, graças à melhoria do estado de saúde "dos negros" - concebidos em seu tratado como sinônimo de escravos (Dazille, 1801). Em Vila Rica, o cirurgião-mor Antônio José Vieira de Carvalho cumpria funções semelhantes às de seu 'colega' de São Domingos e partilhava formação, práticas e anseios igualmente próximos. Tal grau de proximidade talvez tenha contribuído para sua ação de traduzir do francês para o português Observações sobre as enfermidades dos negros.

Entretanto, nessa empresa, Dazille e Vieira de Carvalho não estavam sozinhos. Vários outros cirurgiões, atuantes nos mais variados cantos das possessões lusas, francesas e inglesas, também nos legaram tratados similares ao aqui estudado. Assim, pela confluência dos conteúdos abordados, creio ser plausível considerar tais textos um gênero da literatura médica do século XVIII. Determinados conteúdos podem ser observados de modo repetido nessas páginas, como as advertências sobre os perigos e as especificidades da 'natureza 
tropical' e a forma com que ela fustigava seus habitantes; os cuidados no tratamento de escravos e soldados, tão 'úteis' ao fortalecimento dos ganhos régios além-mar; a relação entre a ação dos médicos e cirurgiões e as outras demandas da administração colonial, entre outros vetores.

Os nomes, descrições e terapêuticas aplicados às doenças que habitam as páginas dessas obras e que nortearam a lida desses autores no tratamento de seus doentes eram balizados, por vezes, por conceitos antiquíssimos que nos colocam novamente diante do legado hipocrático-galênico, como a influência dos humores e a necessidade do conhecimento pormenorizado dos 'ares, águas e lugares' em que atuavam esses curadores. Por outro lado, naquele momento verificava-se o avanço dos estudos anatômicos, com o destacado papel das dissecações para o conhecimento do corpo doente; a imposição de métodos cada vez mais regrados para o exame, sem contar com copiosos registros, coleta de dados, produção de estatísticas, a afirmar um verdadeiro mapeamento e uma 'geografia médica', facetas que trouxeram, a despeito das supracitadas permanências, cores próprias à medicina ilustrada, fosse desta ou daquela margem do Atlântico.

\section{AGRADECIMENTOS}

Agradeço a Lorelai Kury a leitura atenta, bem como críticas e sugestões para a produção deste trabalho.

\section{NOTAS}

${ }^{1}$ Nesta e nas demais citações de textos em inglês, a tradução é livre.

${ }^{2}$ Concordo aqui com as análises de Cunningham e Williams (1992, p.210 e ss.), que alertam sobre o perigo de tomarmos o "familiar" (doença moderna) - fortemente moldado pelo diagnóstico laboratorial e pela percepção da infecção por microrganismos - e aplicarmos ao "não familiar" (doença do passado), convertendo, assim, o "não familiar em familiar".

${ }^{3}$ O que não eliminava a existência de grandes dificuldades e descaminhos na realização dos objetivos de publicação e difusão do pensamento ilustrado em terras lusas, envolvendo diretamente o papel da Tipografia do Arco do Cego. Conferir, entre outros autores, Wegner (2004) e Ferraz (1997).

${ }^{4}$ Penso aqui a ampla e complexa Ilustração, como a considera Lorelai Kury (2007, p.12): "Longe de designar somente um conjunto de ideias, as Luzes englobam, é certo, conceitos, mas também modos de agir".

${ }^{5}$ É fundamental levar em consideração que me norteio pela observação dos conteúdos presentes em alguns desses tratados para defender a hipótese de pensarmos sobre eles como um gênero de literatura médica da segunda metade do século XVIII. Por outro lado, acredito que uma análise mais pormenorizada dos seus aspectos formais e de suas regras de escrita possa proporcionar novos e importantes horizontes de pesquisa. Entretanto, por hora, limito-me aos argumentos e inferências aqui apresentados. Para uma discussão sobre a percepção de textos usados como fontes históricas como gênero literário, conferir Pécora, 2001, p.17-68.

${ }^{6}$ A esse respeito, ver também Arnold, 1996, p.149-158.

${ }^{7}$ Sobre as relações entre tráfico negreiro e condições de saúde, conferir Rodrigues, 2005. Para uma problematização da percepção de algumas doenças - incluindo o escorbuto - como 'doenças africanas' em análises historiográficas, conferir o ensaio de Carvalho, 2007.

${ }^{8}$ Nas palavras do autor: "A patologia não abriu a porta para a cura - dificilmente algum avanço científico do século XVIII ajudou a curar o doente diretamente" (Porter, 1999, p.266). 


\section{REFERÊNCIAS}

ABREU, Jean Luis Neves.

Ilustração, experimentalismo e mecanicismo: aspectos das transformações do saber médico em Portugal no século XVIII. Topoi, Rio de Janeiro, v.8, n.15, p.80-104. 2007.

ARNOLD, David.

Warm climates and western medicine. Atlanta: Rodopi. 1996.

CAIRUS, Henrique.

Textos hipocráticos: o doente, o médico e a doença. Rio de Janeiro: Fiocruz. 2005.

CALAFATE, Pedro.

A idéia de natureza no século XVIII em Portugal. Lisboa: Imprensa Nacional/Casa da Moeda. 1994.

CAMPOS, Fernanda Maria; PAES LEME, Margarida O.R.

Percursos do poder e do saber nos finais do século XVIII: o papel da Impressão Régia e da Casa Literária do Arco do Cego. In: Actas do Colóquio "A Casa Literária do Arco do Cego". Anais, Lisboa, v.7-8. p.111-123. (série História). 2001.

CARVALHO, Diana Maul de.

Doenças dos escravizados, doenças africanas? In: Porto, Ângela (Org.). Doenças e escravidão: sistema de saúde e práticas terapêuticas. Rio de Janeiro: Casa de Oswaldo Cruz/Fiocruz. CDROM. p.1-21. 2007.

CUNNINGHAM, Andrew; WILliAMS, Perry (Ed.).

The laboratory revolution in medicine. Cambridge: Cambridge University Press. 1992.

CURTO, Diogo R. D.

Rodrigo de Souza Coutinho e a Casa Literária do Arco do Cego. In: Campos, Fernanda M.G. de. A Casa Literária do Arco do Cego (17991801). Lisboa: Imprensa Nacional/Casa da Moeda. p.15-49. 1999.

DAZILLE, Jean Barthélemy.

Observações sobre as enfermidades dos negros. Trad., Antônio José Vieira de Carvalho. Lisboa: Tipografia Arco do Cego. 1801.

DIAS, Maria Odila da Silva.

Aspectos da Ilustração no Brasil. Revista do IHGB, Rio de Janeiro, v.278, p.105-170. 1968.

DOMINGUES, Ângela.

Para um melhor conhecimento dos domínios coloniais: a constituição de redes de informação no Império português em finais do Setecentos. /História, Ciências, SaúdeManguinhos, Rio de Janeiro, v.8, supl., p.823838. 2001.
EUGÊNIO, Alisson.

As doenças de escravos como problema médico em Minas Gerais no final do século das luzes. Varia Historia, Belo Horizonte, n.23, p.154-163. 2000.

FERRAZ, Márcia H. Mendes. As ciências em Portugal e no Brasil (1772-1822): o texto conflituoso da química. São Paulo: Educ/ Fapesp. 1997.

FERREIRA, Luís Gomes.

Erário mineral. Belo Horizonte: Fundação João Pinheiro. 1., ed. 1753. 2002.

FIGUEIREDO, Betânia Gonçalves.

$A$ arte de curar: cirurgiões, médicos, boticários e curandeiros no século XIX em Minas Gerais. Rio de Janeiro: Vício de Leitura. 2002.

FLECK, Ludwik.

La gênesis y el desarrollo de um hecho científico. Madri: Alianza Editorial. 1986.

FOUCAULT, Michel.

O nascimento da clínica. Rio de Janeiro: Forense Universitária. 2004.

FOUCAULT, Michel.

Microfísica do poder. Rio de Janeiro: Graal. 2000.

GAVROGLU, Kostas et al.

Science and technology in the European periphery: some historiographical reflections. History of Science, Cambridge, n.46, p.153-175. 2008.

HANNAWAY, Caroline.

Environment and miasmata. In: Bynun, William F.; Porter, Roy. Companion encyclopedia of the history of medicine. Londres: Routledge. p.292-308. 1997.

HARRISON, Mark.

Science and the British Empire. Isis, Chicago, n.96, p.56-63. 2005.

INVENTÁRIO...

Inventário dos bens móveis de Antônio José Vieira de Carvalho, capitão cirurgião mor deste regimento de Cavalaria de Linha de Minas Gerais. In: Revista do Arquivo Público Mineiro, Belo Horizonte, ano 10, fasc.3-4, p.706709.1905 .

JORDANOVA, Ludmilla; PORTER, Roy. Images of the Earth: essays in the history of the environmental sciences. Oxford: Alden Press. 1997.

KURY, Lorelai.

Iluminismo e império no Brasil: O Patriota (18131814). Rio de Janeiro: Editora Fiocruz. 2007. 
KURY, Lorelai.

Homens de ciência no Brasil: impérios coloniais e circulação de informações (1780-1810). História, Ciências, Saúde - Manguinhos, Rio de Janeiro, v.1, n.1, p.109-129. 2004.

KURY, Lorelai.

O império dos miasmas: a Academia Imperial de Medicina (1830-1850). Dissertação (Mestrado) Departamento de História, Universidade Federal Fluminense, Niterói. 1990.

LUNA, Fernando J.; KURY, Lorelai. Enlightenment chemistry translated by a Brazilian man of science in Lisbon. Ambix, Cambridge, v.59, n.3. p.218-240. 2012.

MARQUES, Vera Regina Beltrão.

Educar para a saúde em manuais domésticos do Setecentos. In: Reunião Anual da ANPEd, 28., 2005, Caxambu. Anais... Caxambu: Associação Nacional de Pós-Graduação e Pesquisa em Educação. p.1-18. 2005.

MARQUESE, Rafael Bivar.

Feitores do corpo, missionários da mente: senhores, letrados e o controle dos escravos nas Américas, 1660-1860. São Paulo: Companhia das Letras. 2004.

MENDES, Luís Antonio de Oliveira. Discurso sobre as doenças dos pretos tirados da África. 1.ed., 1812. In: Cardoso, José Luís (Org). Memórias econômicas inéditas. Lisboa: Publicações do Segundo Centenário da Academia de Ciências de Lisboa. p. 22-47. 1987.

MUNTEAL FILHO, Oswaldo.

A Academia Real das Ciências de Lisboa e o império colonial ultramarino (1779-1808). In: Furtado, Júnia (Org.). Diálogos oceânicos: Minas Gerais e as novas abordagens para uma história do império ultramarino português. Belo Horizonte: EdUFMG. p.483-518. 2001.

NUMES, Maria de Fátima; BRIGOLA, João Carlos.

José Mariano da Conceição Veloso (1742-1811): um frade no universo da natureza. In: Campos, Fernanda M. G. de (Org.). A Casa Literária do Arco do Cego (1799-1801). Lisboa: Imprensa Nacional/Casa da Moeda. p.51-75. 1999.

NUTTON, Vivian.

Humoralism. In: Bynun, William F.; Porter, Roy. Companion encyclopedia of the History of Medicine. Londres: Routledge. p.281-291. 1997.

PÉCORA, Alcir.

Máquina de gêneros. São Paulo: EdUSP. 2001.

PIMENTA, Tânia.

Terapeutas populares e instituições médicas na primeira metade do século XIX. In: Chalhoub,
Sidney et al. Artes e ofícios de curar no Brasil. São Paulo: EdUnicamp. p.309-330. 2003.

PORTER, ROY.

The greatest benefit to mankind: a medical history of humanity. Nova York: W.W. Norton. 1999.

PRATT, Mary.

Os olhos do império: relatos de viagem e transculturação. Bauru: EdUSC. 1999.

RAJ, Kapil.

Relocating modern science: circulation and the construction of knowledge in South Asia and Europe, 1650-1900. New York: Palgrave Macmillan. 2007.

\section{REGIMENTO...}

Regimento dos preços porque os boticários do Brasil hão de vender os medicamentos... Seção Colonial, cód. 02 fls. 205-224v. (Arquivo Público Mineiro). 1742.

RIBEIRO, Márcia Moisés.

Exorcistas e demônios: demonologia e exorcismo no mundo luso-brasileiro. Rio de Janeiro:

Campus. 2003.

RODRIGUES, Jaime.

De costa a costa: escravos, marinheiros e intermediários do tráfico negreiro de Angola para o Rio de Janeiro (1780-1860). São Paulo: Companhia das Letras. 2005.

ROSEMBERG, Charles.

Framing disease: illness, society and history. In: Explanning epidemics and others studies in the history of medicine. Cambridge: Cambridge University Press. p.305-318. 1992.

ROSSI, Paolo.

O nascimento da ciência moderna na Europa. São Paulo: EdUSC. 2001.

VELOSO, José Mariano da Conceição. Colleção de memórias sobre a Quassia Amarga e Simaruba.... Lisboa: Tipografia Arco do Cego. 1801.

WEGNER, Robert.

Livros do Arco do Cego no Brasil colonial. História, Ciências, Saúde - Manguinhos, Rio de Janeiro, v.11, supl.1, p.131-140. 2004.

WEINER, Doara B.; SAUTER, Michael J. The city of Paris and the rise of clinical medicine. Osiris, Chicago, n.18, p.23-42. 2003. 